\title{
23 \\ Journal Writing as Taking Ownership of Internship Experiences
}

\author{
Tracey Bowen \\ University of Toronto
}

Many disciplines employ journal writing as a tool for students to record and reflect on their learning experiences. In the internship program in Communications Culture and Information Technology at the University of Toronto Mississauga students experience the transfer of classroom theory to practice in the "real" work world during a once a week placement. Students use journals to account for these experiences reflecting on the knowledge they gain from their observations and how this knowledge incorporates into everyday work life. However, journal writing has pedagogical affordances that extend beyond recording and reflecting on experience. Language mediates the learning as students choose what to say about what they experience. They take ownership of these connections and make meaning by appropriating these ideas as part of who they are and who they are becoming as industry professionals. Identifying the ways in which students use journal writing to construct their professional selves will contribute to the evolving scholarship of experiential education.

\section{Introduction}

$\mathrm{T}$ he Communications Culture and Information Technology (CCIT) program at the University of Toronto at Mississauga offers an internship course, where select fourth-year students earn academic credit in an experiential work placement during the 13 week academic term. The students complete 100 hours of unpaid work, attend class meetings, and complete four assignments. One of the primary objectives of the internship program is for students to examine the translation of classroom-based theory to practical applications in the work world along with gaining "hands-on" industry experience. Students account for these experiences through a written journal, an oral presentation, and a final research report. Clark and Whitelegg (1998) named this kind of experiential learning 'work-based' learning. Both researchers have been promoting work-based learning throughout the UK as an important part of academic study, even if some consider it "an undesirable dilution of the academic rigor of the honours degree sys- 
tem" (p. 325). Their research confirms the concerns of many North American employers that students are lacking an understanding of the requirements of the real work world and are graduating knowing only a part of the education equation. CCIT students begin to develop an understanding of life outside the academy through their initial placement searches ,which require them to assess their skill sets, research appropriate companies and positions and look for a possible match. These skills are not typically part of any academic curriculum. Students experience intense contact with their placement supervisors who act as trainers and mentors. According to Clark and Whitelegg, this is the most desirable arrangement for a successful learning experience. The CCIT internship program is not like other Co-op programs as CCIT students maintain a regular academic schedule of courses in conjunction with their work placement responsibilities.

Work/learning journals used within experiential learning programs such as the CCIT internship, provide a space where students can explore, identify, and make sense of the connections between their academic education and several core competencies required by the 'real' professional work world. Writing about the connections provides students with the opportunity to move from the position of seeing themselves as students to perceiving themselves as professionals in the work world. My initial examination of CCIT students' journals over the past two years illustrates how the work journals can be used as a form of student inquiry that requires them to plot their observations, reflect on what they are learning , and analyze how they learn across different contexts.

\section{Writing as a Mediator of Social Experience}

James Paul Gee (2000) adopts a Vygotskian approach to writing as a mediator of social experience, that is, an understanding of writing as a mediating activity that enables students to give shape to their experiences for meaning making. Thinking, he (Gee) contends, is "almost always mediated by 'cultural tools,' that is artifacts, symbols, tools, technologies, and forms of language that have been historically and culturally shaped to carry out certain functions and carry certain meanings (cultural tools have certain 'affordances' although people can transform them through using them in new settings)" (p. 181). van Lier (2004) maintains that "[a]ffordances are those relationships that provide a 'match' between something in the environment (whether it's a chair or an utterance) and the learner. The affordance fuels perception and activity, and brings about meanings - further affordances and signs, and further higher-level activity as well as more differentiated perception" (p. 96).

Students use the tools, technologies, and language offered to them by the academic culture. Writing about the connections between theories studied in lectures, terminology professed by experts and software used for class assignments provides an opportunity to organize, analyze and evaluate the information they are ingesting in relation to everyday work world applications. Students may ask why it is important that they acquire this information as they learn how the information is utilized across different contexts. Most importantly, students may use the space afforded by journaling to see how they can produce new information, symbols, tools, and technologies that contribute to the changing industry sector.

Writing is a form of information processing that facilitates thought processes and affords opportunities to develop and change ideas and question and alter worldviews (Logan 2000). Vygotsky viewed language as the completion of thought - a way of organizing thoughts for meaning making. I see reflective and analytical writing in particular as ways for students to move beyond experiencing an event, toward understanding what the event means and how it affects what they already know about the world. Using a Vygotskian lens, journal writing is a way of using language to complete thought. The objective of the work journals is to make students conscious of how they learn through their experiences and interactions within the workplace. Language mediates the learning as students choose what to say about what they experience. Reflecting back on the journals enables students to track their learning patterns and processes of personal growth. The work/learning journal pro- 
vides a space for students to think.

Gee (2000) also claims that individuals create narratives to "make sense of their experiences of other people and the world by emplotting them in terms of socially and culturally specific stories, stories which are supported by the social practices, rituals, texts and other media representations of specific groups and cultures" (p. 182). The internship students experience very particular work culture practices that become part of their storied experiences of work activities. Writing about the work culture they observe and experience enables students to understand how they are also implicated in the social structure of their placement environment and how their own ways of working and interacting contribute to the perpetuation of these cultural practices. Examining the work culture also enables students to see opportunities for change. The learning journals are a site for exploring what else is possible.

\section{Making Connections}

Students who recognize the connections between what they learn in the classroom and the transferable skills needed within the work world are more likely to become active participants in their own learning (D’Aloisio, 2006). D'Aloisio describes four primary categories of core competencies inherent within higher education learning that can be linked to core competencies needed within the business world. These four categories include "self-management, information management, communication and teamwork" (p. 226). Self-management and communication are crucial for students juggling internship placement work with a rigorous academic schedule. However the transfer of these skills is not always evident through the practical experience alone. Reflecting on the challenges through narrative-based writing enables students to see how they are adapting and coping as well as learning and succeeding throughout the experience.

Many disciplines employ journal writing as a tool for students to record and reflect on their learning experiences. Journal writing enables students to "work out" their ideas and describe their problem- solving approaches as they develop a reflective practice of consciously analyzing their learning process (Park, 2003). Students use their work journals to apply the information they collect from their work experience and compare these applications with the theories, "symbols, tools, technologies, and [forms of] language" (Gee, 2000, p. 181) studied within the academic context. They become research/participants within their industry sectors, always observing, describing, noting, analyzing, reflecting, and rethinking the events around them.

Many students also write what Park (2003) calls "confessional material" (p. 190). This part of the narrative reveals aspects of their learning and coping strategies that might not otherwise surface in other written assignments. The confessionals afford "scope for catharsis, by voicing fears and then moving on past them" (Park, 2003, p. 190). Writing is a way for students to make sense of what they are doing and where they are going as they document their thoughts, ideas and conundrums over time.

Students contextualize their learning through their writing. They may use writing as a mediating activity that enables them to take ownership of the connections they discover. Gelmon, Holland, Driscoll, Spring, and Kerrigan (2006) explain that taking ownership may be measured by the student's "expressed autonomy and independence" (p. 24). This is evident in the language the students use when they write about gaining confidence in their role as an industry worker, when they have mastered new skill sets and when they complete tasks and problem solve independent of their placement supervisors. Journaling provides a space for students to appropriate these new ideas and potentially explore new identity constructions. The pedagogical implications of journal writing in relation to students' abilities to make meaning of their real life work experiences are crucial to their self-directed learning within the program. Journaling their experiences affords students the opportunity "to see learning as a never-ending journey that does not necessarily stop outside the classroom or after they have graduated" (Cisero, 2006, p. 231). Motivating students to analyze the transfer of academic skills to core workplace competencies in particular will help them construct meaning around their educational ca- 
reers. The potential outcomes are that students take ownership of and become accountable for their ideas and actions beyond the academy. Furthermore, understanding how they translate skills developed within the academic "bubble" to the practical needs of the "real" work world will help students prepare for future professional encounters such as writing letters of introduction and answering interview questions.

\section{Student Voices}

Students are asked to describe, reflect, and critically analyze their activities and interactions for each journal entry. They begin the first entry with their learning objectives and then return to those objectives throughout the term as they assess their progress. For many students, the writing becomes more cathartic as they progress throughout the term. The following two samples of student work address common issues including self-directed learning, assessing skills, recognition by colleagues, developing personal goals and meeting expectations.

\section{Susan}

"Attention to detail" is repeated time and time again in the job qualification descriptions that I have found through my searches. I always assumed that I had this skill even though I did not really know what it was explicitly referring to. Unless I have learned it in school, I do not know that I can do it. Working on [corporate] fact sheets, however, has helped me both define and enhance my attention to detail... When I read a sentence in my fact sheets I summon all of the information about the company that I know - both implicit and explicit facts and culture - and make sure that the phrase or sentence at hand is aligned with these practices ... to many this may seem unimportant or menial (not the skill, but understanding the skill) but it will prove to be useful to me when I am in interviews and able to describe how this process works and how I am able to do this.

\section{Peter}

Reflecting on my experience interacting with new volunteers again today, I've come to realize that the more informed and assertive a leader is, the more willing their followers seem to be. I say 'seem' simply because I'm personally making this judgment that the volunteers were willing to do what I asked. However, I credit my specific knowledgeable directions with obtaining the new volunteers cooperation ... I've determined that acting confident, regardless of whether or not I am, will play a crucial role in my ability to lead others. This does not suggest that I should fake knowledge to ensure others continue to follow my lead. In a situation where my knowledge is lacking, I would not suggest such claims to those working for me. Instead, I would leave the situation, obtain the necessary resources to provide accurate direction and continue leading with the new information...Considering my interactions with new volunteers as a learning experience in leadership, I've become curious as to how other great leaders have structured their leadership abilities. Not everyone leads a group the same way. I would like to be as informed as possible before jumping into any major leadership commitments. I think I will focus much more on my ability to lead others in the future.

Both Susan and Peter use their work journals as a site for thinking and reflection. They wrestle with particular concepts that are meaningful to them by identifying a problem or conundrum, exploring possibilities and then writing their way to some sort of a resolution - it is writing as inquiry. Each incident becomes part of a learning continuum for the students who are working to figure out their positions in a world beyond academia.

Park (2003) names several positive outcomes of students writing about their work placement experiences. I perceive three of these outcomes as occurring in the work submitted by the CCIT internship students. The first is ownership. Students take ownership of their learning and their experiences when they state their learning objectives. They reflect on what they expect to learn from the internship experience in terms of developing hard and soft skills, gaining leadership experience, gaining teamwork experience and understanding best practices within the industry. The second important outcome of the work/ 
learning journal writing activity is the students' increased awareness of their learning. They show evidence of understanding how they learn and what it means to become a self-directed learner within the workplace. Through their writing they analyze the problems and obstacles they encounter and articulate the process of finding possible solutions. They appear to recognize this aspect of problem solving as a reflective practice.

The third important outcome of the work/ learning journals is realizing an increase in self confidence. The students see their personal growth in the written reflections of how they have handled difficult situations. They begin to see themselves as professionals that contribute to the industry. More advanced and astute students also recognize cathartic and transformational moments within their written accounts and begin to see journal writing as a form of industry research that will aid them throughout their careers.

As more students engage in experiencebased learning, further research into journal writing as a form of student inquiry is warranted. The once mostly descriptive diarizing is shifting to more rigorous examination and analysis of industry practices and standards, organizational behaviour, leadership strategies and self-directed learning. The Internship placement journal is a space that offers students the opportunity to engage in a form of qualitative inquiry that requires them to formulate problems, collect data through observations, analyze that data in the service of meaning making and form conclusions which for some, induces transformative learning.

\section{References}

Cisero, C. (2006). Does reflective journal writing improve course performance? College Teaching, 54(2), 231-236.

Clark, G. \& Whitelegg, J. (1998). Maximizing the benefits from work-based learning: The effectiveness of environmental audits. Journal of Geography in Higher Education, 22(3), 325334.
D’Aloisio, A. (2006). Motivating students through awareness of the natural correlation between college learning and corporate work settings. College Teaching, 54(2), 225-229.

Gee, J.P. (2000). The new literacy studies: From 'socially situated' to the work of the social. In D. Barton, M. Hamilton, \& R. Ivanič (Eds.), Situated literacies: Reading and writing in context. London: Routledge.

Gelmon, S., Holland, B., Driscoll, A., Spring, A., \& Kerrigan, S. (2006). Assessing service-learning and civic engagement, principles and techniques. Campus Compact, RI: Brown University.

Logan, R. (2000). The sixth language. Toronto: Stoddart.

Park, C. (2003). Engaging students in the learning process: The learning journal. Journal of $\mathrm{Ge}$ ography in Higher Education, 27(2), 183-199.

van Lier, L. (2004). The ecology and semiotics of language learning: A sociocultural perspective (Vol. 3). Boston: Kluwer Academic Publishers. 